๑) Open Access Full Text Article

CORRIGENDUM

\title{
Novel Aptamer-Functionalized Nanoparticles Enhances Bone Defect Repair by Improving Stem Cell Recruitment [Corrigendum]
}

Wang $\mathrm{M}, \mathrm{Wu} \mathrm{H}, \mathrm{Li} \mathrm{Q}$, et al. Int $J$ Nanomedicine. 2019;14:8707-8724.

The authors have advised due to an error at the time of figure assembly, Figure 3A and B on page 8714 is incorrect. The correct Figure 3 is shown below.
The authors apologize for this error and advise it does not affect the results of the paper. 
A

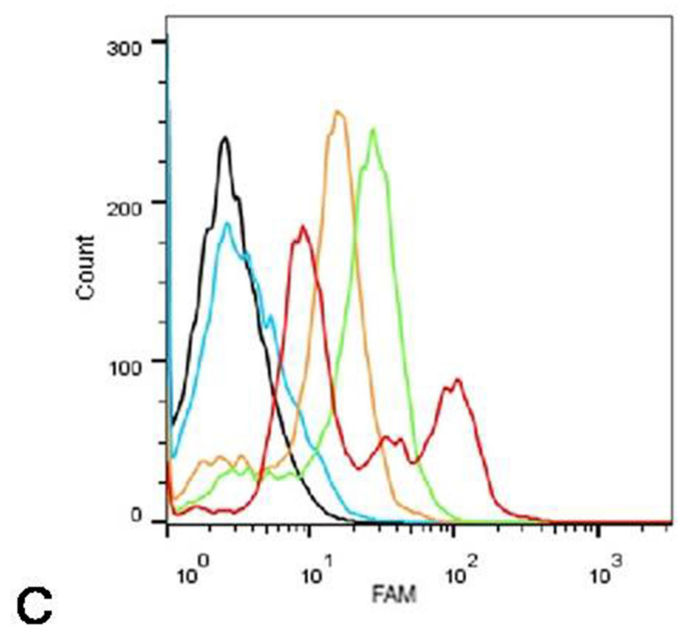

\begin{tabular}{|c|c|c|}
\hline NGS & Sequence (random region 5'-3') & ID \\
\hline Clone 13 & CTGCATAAGCTCTGCAATGGCTCGATCG & HM13 \\
\hline Clone 69 & CATGCCCCTGTAATCGCCCATGGGTAGC & HM69 \\
\hline Clone 77 & AGCGGGTGGACCCCTGATCGGCTAAATG & HM77 \\
\hline Clone 98 & CCGTATAAGCGGCCGCCTAGGGGCTAGA & HM98 \\
\hline Clone 159 & GGCTATAAGCCCTTAGCGGGCTCGCTAA & HM159 \\
\hline Clone 274 & GGGGCTCAACGTACCTAGCGACCGCCGG & HM274 \\
\hline Clone 397 & TTTTCGCATCGCACCTAGCCGGCTAGCT & HM397 \\
\hline
\end{tabular}

B

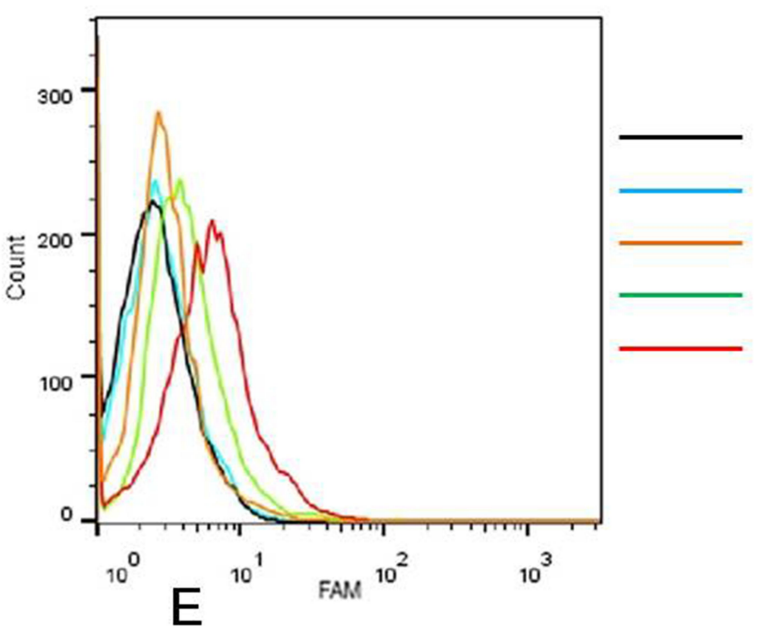

Blank

$2^{\text {med }}$ rounnd $4^{\text {th }}$ in round $6^{\text {th }}$ round $9^{\text {th }}$ round

D

\begin{tabular}{|l|l|l|l|l|l|l|l|l|l|l|l|l|l|l|l|l|l|l|l|l|l|l|l|l|l|l|l|l|}
\hline ID & \multicolumn{10}{|c|}{ Aligned Sequence } \\
\hline HM13 & C & T & G & C & A & T & A & A & G & C & T & C & T & G & C & A & A & T & G & G & C & T & C & G & A & T & C & G \\
\hline HM98 & C & C & G & T & A & T & A & A & G & C & G & G & C & C & G & C & C & T & A & G & G & G & G & C & T & A & G & A \\
\hline HM159 & G & G & C & T & A & T & A & A & G & C & C & C & T & T & A & G & C & G & G & G & C & T & C & G & C & T & A & A \\
\hline HM397 & T & T & T & T & C & G & C & A & T & C & G & C & A & C & C & T & A & G & C & C & G & G & C & T & A & G & C & T \\
\hline HM274 & G & G & G & G & C & T & C & A & A & C & G & T & A & C & C & T & A & G & C & G & A & C & C & G & C & C & G & G \\
\hline HM77 & A & G & C & G & G & G & T & G & G & A & C & C & C & C & T & G & A & T & C & G & G & C & T & A & A & A & T & G \\
\hline HM69 & C & A & T & G & C & C & C & C & T & G & T & A & A & T & C & G & C & C & C & A & T & G & G & G & T & A & G & C \\
\hline
\end{tabular}

Figure 3 Monitoring of SELEX and DNA sequence analysis. (A) Flow cytometry monitoring of the enrichment of aptamers. Compared with the starting random DNA pool (the black curve), flow cytometry revealed an increase in fluorescence intensity of aptamers bound to the MSCs after the second (the blue curve), the forth (the orange curve), the sixth (the green curve), and ninth (the red curve) rounds of selection. (B) Flow cytometry monitoring of the non-specific binding to $293 \mathrm{FT}$ of aptamers. (C) The random sequence of aptamers which were capable of binding MSCs preferentially. (D) The sequence alignment of aptamer candidates. (E) The similarity among the aptamer candidates was analyzed through the homology tree.

International Journal of Nanomedicine

\section{Dovepress}

\section{Publish your work in this journal}

The International Journal of Nanomedicine is an international, peerreviewed journal focusing on the application of nanotechnology in diagnostics, therapeutics, and drug delivery systems throughout the biomedical field. This journal is indexed on PubMed Central, MedLine, CAS, SciSearch ${ }^{\circledR}$, Current Contents ${ }^{\mathbb{B}} /$ Clinical Medicine,
Journal Citation Reports/Science Edition, EMBase, Scopus and the Elsevier Bibliographic databases. The manuscript management system is completely online and includes a very quick and fair peer-review system, which is all easy to use. Visit http://www.dovepress.com/ testimonials.php to read real quotes from published authors. 